\title{
Correction to: Sedimentological impact on reservoir quality of Es1 sandstone of Shahejie formation, Nanpu Sag, East China
}

\author{
Muhammad Kashif ${ }^{1,2} \cdot$ Yingchang Cao ${ }^{1} \cdot$ Guanghui Yuan $^{1} \cdot$ Muhammad Asif $^{4} \cdot$ Wang Jian $^{1} \cdot$ Wang Zhukhun $^{1} \cdot$ \\ Saif Ur Rehman ${ }^{2}$ - Atif Zafar ${ }^{3} \cdot$ Muhammad Kamran $^{5}$ • Orkhan Isgandarov ${ }^{1}$ • Asim Falak Naz ${ }^{1}$
}

Published online: 6 September 2019

(C) Saudi Society for Geosciences 2019

Correction to: Arabian Journal of Geosciences (2019) 12:545 https://doi.org/10.1007/s12517-019-4671-y

The original version of this paper was published with error. The correct spelling of author name is "Orkhan Isgandarov" instead of "Orkhan Isgandrove". Corresponding author failed to provide a correction during proofing stage. Given in this article is the correct name.

The original article has been corrected.

The online version of the original article can be found at https://doi.org/ 10.1007/s12517-019-4671-y

Muhammad Kashif

kashifyaqub@yahoo.com

$\triangle$ Yingchang Cao

caoych@upc.edu.cn

1 School of Geosciences, China University of Petroleum, Qingdao 266580, China

2 Department of Earth Sciences, University of Sargodha, Sargodha 40100, Pakistan

3 School of Petroleum Engineering, China University of Petroleum, Qingdao 266580, China

4 Institute of Geology, University of the Punjab, Lahore 54590, Pakistan

5 School of Earth Sciences and Resources, China university of Geosciences, Beijing 100083, China 